\title{
Contextualising Relationships between Mothers and Practitioners: Social Structures, Causal Factors \& Generative Mechanisms
}

\author{
Wendy Sims-Schouten \& Sarah Barton
}

\begin{abstract}
This study seeks to build an explanation of the sociological, psychological and political processes and practices involved in relationships between mothers and practitioners, as generative and causal powers that underlie and shape this. Critical realist's primacy of ontology forms the starting point, with grounded theory as the epistemological force providing critical realism's method, contextualising research and embedding this more firmly into practice. As such, this article offers critical realist grounded theory (CRGT) as a tool for contextualising parent-practitioner relationships, drawing on retroductive argumentation, which involves moving from the level of observation and lived experiences to making (nonlinear) inferences about underlying structures/mechanisms that may account for the phenomena. Thirty-four participants participated in six in-depth focus group discussions; three were with early years practitioners and three with mothers of children aged between 2-4 years old. Focused coding led to themes reflecting the lived experiences of mothers and practitioners, namely being valued, relationships, what happens at home, child at the centre and when I am not there. In line with CRGT, multiple causal mechanisms (including the interpretations of each situation made by individuals) were identified that were active in the situated contexts. In order to improve relationships between mothers and practitioners, attention needs to be paid to the psychological, social and political forces at play, as generative, causal and contextual powers, that have an impact on the status and relationships of the players within this triad (mothers, practitioners and child).
\end{abstract}

\section{Introduction}

The study of social structures, context and social stratification, and related power and status, is at the heart of sociological research. Implicit in this is the role of social interactions, giving rise to or eliciting particular emotions and social relational outcomes (Jacoby, 2016). Whilst sociology as a discipline tends to characterise interactions and contexts in terms of individual/community or individual/social structure binaries, there will also be forms of belonging and social interactions that fall in between these extremes (Kellet, 2012; Miller, 2015). Relationships between mothers and practitioners are an example of such social interactions that fall in between the binaries of individual/community and individual/social 
structures. The current research poses the following question: Can relationships between mothers and practitioners be contextualised and what (if any) is the role of sociological, psychological and political processes and practices in this interaction? With increasing numbers of children now spending at least part of the day in day-care, early years care and education, as well as parent-partnerships, have been high on British political agendas (Kochanska and Kim, 2012; Bate, 2017). At the same time research has shown that the primary care system needs to be improved so as to better support children's transitions from home to day-care (Ebbeck and Yim, 2009; Osgood, 2009; Spiteri and Borg Xuereb, 2011). There is evidence that the status of the early years workforce is low and working in the early years is too often seen as a low-level job which involves, as some have expressed, 'wiping noses' and 'playing with kids', and it is not necessarily regarded as a professional occupation that demands good qualifications and expertise (Nutbrown, 2012). In practice, this means that parent participation has moved from the psychological to the political arena, and it has become important for early years practitioners to have a clear understanding of how to improve effective communication with parents about supporting children in their learning (Kennedy Reedy and Hobbins McGrath, 2010; Whalley, 2007).

Influential research in the British early years sector (such as the Effective Provision of Preschool Education project, a longitudinal study of the overall effect of different types of preschool provision on child development in England and Wales, see Siraj-Blatchford, 2009; Sylva et al., 2010), is largely quantitative in nature ignoring the necessity of incorporating context and process into an understanding of parent-practitioner partnerships and parents' engagement with services. Qualitative research highlights the ongoing discrepancy between practitioners' and parents' positive commitment to children's learning and development, and the continued focus (in political and psychological discourse) on the fact that they are lacking 
in ability and in need of transformation (Osgood, 2009; Sims-Schouten and Stittrich-Lyons, 2013).

Notwithstanding the breadth and richness of literature in early childhood, there remains an important lacuna within it, namely detailed research on the role of the social context and related processes as causal powers and generative mechanisms. The emphasis on context and process of a phenomenon is reflected most strongly in the methodology of critical realist informed grounded theory (Kempster and Parry, 2014). This study is novel in that it seeks to build an explanation of the social, psychological and political processes and practices involved in relationships between mothers and practitioners, as generative and causal powers that underlie and shape this. Critical realist informed grounded theory draws on retroductive argumentation, which involves moving from the level of observation and lived experiences to making (non-linear) inferences about underlying structures and mechanisms that may account for the phenomena involved (Bhaskar, 1989; 2014). The theory resulting from critical realist informed grounded theory is a conceptually dense analytical explanation of the actual events represented in the data; its relatively enduring capability in this regard can be evaluated by confronting it with new data (Lee, 2012).

\section{Critical Realism and the Interplay between Human Agency and Social Structures}

This study offers critical realist informed grounded theory as a tool for contextualising professional relationships, using partnerships between mothers and practitioners in the British early years sector as an example. The research design aims to identify causal mechanisms that are active in the situated context. Key principles of critical realism include the acknowledgement of the existence of a multi-layered 'real world' (ontological assumption), 
which is produced by underlying causal mechanisms (epistemological assumption) (Bhaskar, 1989, 2014; Howard and Davies, 2013). Here, a stratified ontology is assumed, referring to critical realism's distinction between the 'real' (social structures/context with their associated causal powers), the 'actual' (events and processes) and the 'empirical' (the real and actual as experienced by social actors) (Bhaskar, 1989; Sims-Schouten and Riley, 2014). Simply put, for critical realists, phenomena exist at the level of events and experiences, but also at a deeper level that may not be observable; as such, critical realism is also sometimes referred to as post-positivism (Kempster and Parry, 2011). This article is novel in that it presents critical realist grounded theory as a systematic tool for addressing both the event under study (in this case relationships between mothers and practitioners) and the meaning made of it, by viewing this in light of non-linear causal factors, social structures and generative mechanisms. We argue that by exploring causal mechanisms, as both generative and contextual, we can explore how people (in this case mothers and practitioners) manage themselves within a social context that is materially and institutionally structured (referring to the physical nature of the world, as well as government bodies and the psy-complex) and embodied (e.g. the body as a biological machine) (Cromby and Nightingale, 1999). Critical realist's primacy of ontology forms the starting point here, with grounded theory as the epistemological force providing critical realism's method and, in doing so, contextualising research and imbedding this more firmly into practice (Oliver, 2012).

Traditionally, grounded theory has been a method for researching phenomena that are observable (see Glaser and Strauss, 1967); see also Apramian et al. (2016) for an analysis of the four schools of grounded theory. Critical realists focus on understanding and explaining phenomena; here, reality is seen as a result of causal powers, some of which can be observed to cause effect, whereas others are less obvious. Yet, despite the causality of mechanisms, their constitution, structure and interactions are likely to vary by context. In other words, a 
mechanism may be active in one context and not in another. Mothers and early years practitioners are the focal point of this paper, and in particular how they conceptualise their own role and professional relationships (and 'context') when engaging with the early years sector. It is suggested that children benefit the most from their experience in day-care if their parents are actively involved (Nalls et al., 2010). However, this is only the case when parental involvement is reciprocal, constructive and empowering (Sims-Schouten and Riley, 2014; Sims-Schouten, 2016). In essence, this means reflecting with parents (in this case mothers) and early years practitioners on their engagement with services, and finding out what works or does not work for adults in a range of family contexts and with a variety of life experiences.

In critical realist language a context consists of a set of relationships and embedded practices which have a 'real' power to cause an effect through an interaction of structure and agency (Kempster and Parry, 2014; Kessler and Bach, 2014). Here specific causal mechanisms may be inferred by exploring similarities and differences between how people conceptualise, and add meaning to, their experience of specific phenomena and the contextual structures within which these structures are realised (see Howard and Davies, 2013). Not only that, context is structured from a set of internal and external relations - the relationship between parents and practitioners is external in the sense that either can exist without the other; in contrast the relation between a parent and a child is internal, in that a person cannot be a parent without (having had) a child.

Grounded theory utilises an abductive logic, with a focus on the dialogue between ideas and data, representing a consistent set of data collection and analytical procedures to developing theory (Charmaz, 2006; Reichertz, 2010). Critical realist grounded theory (CRGT) allows for the explanation of the social processes that occur within a particular context, providing a tool through which causal powers at specific contextual levels of analysis can be examined, as 
well as explaining why in certain contexts generative powers have effect and not in others (Kempster and Parry, 2014). As such, critical realism provides the ontological realist foundation for grounded theory, identifying its objects for empirical grounding, structures and causal mechanisms, whilst grounded theory provides the research strategy by which they are empirically grounded (Lee, 2012).

\section{Method: Applying CRGT}

Below we present our CRGT framework, which is applied to data from focus group interviews with mothers and early years practitioners in the South-East of England. Thirtyfour participants were in six in-depth focus group discussions, three were with early years practitioners, and three with mothers of children aged between 2-4 years old; there were between 4-7 participants in each focus group. The interviews were semi-structured with a focus on day-care choices, relationships between mothers and practitioners, and supporting the child; the data were analysed drawing on CRGT as a methodological framework (SimsSchouten and Riley, 2014; Bhaskar, 1989; Kepster and Parry, 2011; 2014). Grounded theory methods are suited to focus group data collection and analysis; focus groups enable participants to respond to ideas shared by other members of the group, as well as providing insight into the experiences of individual participants (Kitzinger, 1994).

The focus groups with the early years practitioner were mixed gender; participants in both groups were a mix of white and BME (black, Asian and minority ethnic minority) participants. Early years practitioners were either childminders, catering for children in their own homes or worked in day-care centres, and were contacted through the placement officer in our University. Mothers were contacted through the early years practitioners. In consultation with the participants, it was decided to run the interviews with the mothers in a 
day-care centre located in a central (i.e. easy to access) part of the city; the interviews with the early years practitioners took place at the University. The early years practitioners worked in different settings and did not know each other; similarly, the mothers were not familiar with each other. In line with grounded theory, theoretical sampling was applied, with a focus on developing a conceptual theory as opposed to creating a descriptive account (Glaser and Strauss, 1967). Here theoretical sampling could be viewed as purpose-driven, and the sample is selected for the purpose of explicating and refining the emerging theory (Breckenridge and Jones, 2009). Ethical principles were adhered to throughout the study; informed consent was obtained and participants were informed of their right to withdraw.

A key premise of grounded theory is to allow issues to emerge from the data, rather than forcing this into preconceived categories. In line with Charmaz (2006) we applied line-byline coding, building our analysis from the ground up, leading into focused coding allowing us to create and try out categories for capturing our data. Combining critical realism and grounded theory, our goal is to identify instances of the phenomenon under investigation and subsequently determine which conditions precede its appearance, drawing on an adaptation of the four stages of retroductive argumentation proposed by Kempster and Parry (2014):

1. Description of the phenomenon - in this case, mothers and early years' practitioners' perspectives regarding their own position and relationships in early years' settings.

2. Description of causal powers that produce the phenomenon, i.e. positioning and relationships, or are a condition for it.

3. Theories and concepts are developed to explain how 'real' causal powers shape mothers' and practitioners' lived experiences in relation to working together.

4. The theories are tested in reality against a pragmatic common reference in order to establish if the causal mechanisms make sense. 
The latter (point 4), is achieved through the iterative nature of testing, with emerging explanations from respondents occurring throughout the research process. In practice this means adopting an iterative dynamic process throughout, leading firstly to possible themes, secondly to read extant literature that suggests possible themes and thirdly to revisit the data and question initial interpretations (Kempster and Parry, 2014, 100). In order to fit in with stage 4 of the retroductive argumentation (the iterative nature of testing), participants were consulted throughout the analysis of the data. As such, this research sought to triangulate the emerging theory across the range of participants. It is at this stage, that the retroductive movement of going beyond the data occurred in order to derive generative mechanisms and causal factors that may explain the phenomenon (Sims-Schouten and Riley, 2014). It should be noted here that in traditional grounded theory (Charmaz, 2006; Glaser and Strauss 1967) there is an expectation to bracket out theory. Yet, this is not necessarily the case for critical realists; instead, theory and metaphor are perceived as essential to help explore beyond the empirical domain and establish what causal powers play a role here. As such, as well as addressing grounded theory's notions in relation to observable phenomena/events, we focus on 'real' and 'deep' causal factors and powers that are often unobserved (Oliver, 2012).

\section{CRGT in Action: Themes, Causal Powers \& Generative Mechanisms}

A number of themes were identified, namely: 'being valued'; 'relationships'; 'what happens at home'; 'child at the centre'; 'when I am not there'. Numerous iterations of conceptualisations, which included testing the theories in reality against a pragmatic common referent (stage 4 of the retroductive argumentation - Kempster and Parry, 2014), led to the distillation of potential causal factors impacting on the themes, for example: 
1. Self-concept - causal powers connected with notions of self-esteem and academic achievement (Marsh and Martin, 2011), as well as self-efficacy (Bandura, 1997).

2. Political agenda - causal powers associated with status and raising the qualifications of early years practitioners in England, and an increased focus on parent-partnerships (DfES, 2017; Nutbrown, 2012; Osgood, 2009).

3. Early Years Curriculum - causal dynamics enforced by the early years foundation stage (DfE, 2017; Sylva et al., 2010), with a goal to developing the skills and capacities children need to develop and become ready for school.

4. Psychological structures - early childhood as a formative phase; attachment theory and the role of early relationships (Bowlby, 2005; Fearon et al., 2010; Keller, 2012).

5. Family structure - which includes hierarchies, boundaries, subsystems, homeostasis, equifinity/ equipotentiality, as well as social economic situation, resources and family resilience (Burr et al.,1993; Whalley, 2007).

6. Structure-agency relationship (see Kempster and Parry, 2014) - including causal powers to do with morphogenesis (the ability of a system to change its form) and morphostasis (the ability of a system to hold its shape).

Causal powers and configurations are central within the critical realist approach, and allow for an examination of the generative powers that have an effect in one context and not in another. As can be seen from the figure below, some causal powers play a role in both contexts, e.g. the early years curriculum and associated guidelines and regulations, the role of psychological theories, as well as self-concept. At the same time, academic achievement and associated self-efficacy, as well as experience and career and the low status of early years practitioners in England were generative powers in the early years context, whilst family structure, needs of the child and family and SES played more of a role in the mother context. 
Figure 1: Contrastive Causal Configurations of Positioning and Relationships

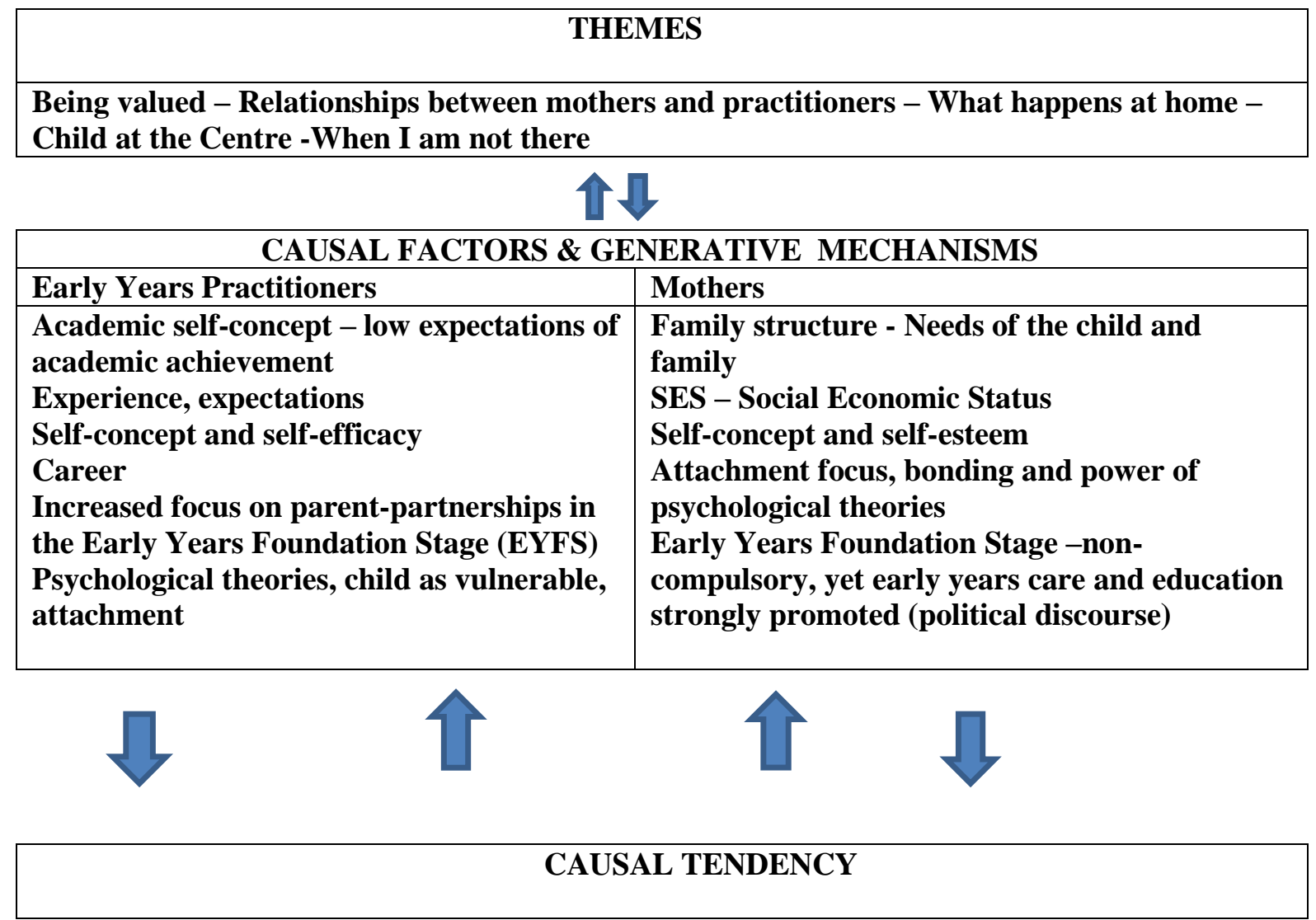
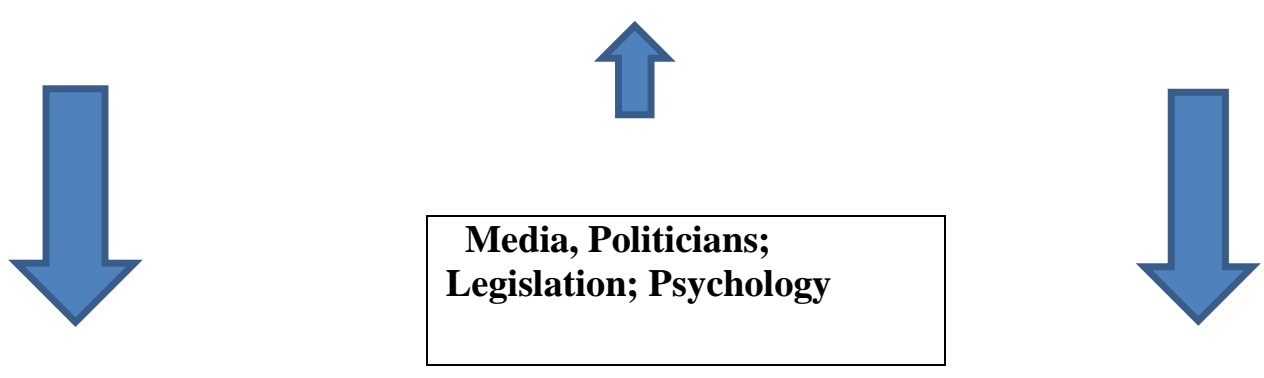

Outcome: Relationships between Mothers \& Practitioners

Below we provide examples to showcase applications of the CRGT tool. We will analyse this against the causal factors, generative mechanisms and (literature) frames of reference (items 1-6) identified above. In line with Pitchforth, Porter, Van Teijlingen \& Forrest Keenan 
(2005), we will use the following unique identifiers for each focus group: FG1M, FG2M, and FG3M refer to the focus groups with the mothers, and FG1P, FG2P and FG3P refer to the focus groups with the practitioners.

\section{Being valued:}

Both early years practitioners and mothers talked about being valued. Interestingly, for both groups this was very much related to how they were perceived by (other) parents. The first extract comes from a FG1P, and is part of a discussion around working with parents:

P1: I have always been very good with children, I work well with kids, but I am not always confident when it comes to advising parents, I mean, I can talk about what their child has done all day and stuff, but I don't always think that they are interested or take me seriously really, after all I am only a childminder.

Confidence as a concept and element of professional identity and perceived competence appears a number of times in the interviews with the practitioners - below is another example.

P2: I have always been a very confident person, but in this particular field I believe I have had a huge mountain to climb.

Traditionally, the status of workers in early childhood services in England has been low.

There appears to be an ongoing discrepancy, as is also evident from the extract above, between practitioners' positive commitment to their work with children and the fact that they are lacking in professional knowledge (Sims-Schouten, 2016). Working in the early years is too often seen as a low level job, rather than as a professional occupation that demands good qualifications and expertise (see also Nutbrown, 2012). Despite the recent focus on early years professional development, a discrepancy remains between practitioners' positive commitment to their own professional development (Mahadevan 2011), and the continued focus on the fact that they are lacking and in need of transformation (Allen 2011; Osgood 2009). Not only does this appear to affect how practitioners are perceived or 'being valued' by the parent, there is also the link with confidence, academic standing and self- esteem as a 
causal factor (1). Thus, in the 'structure-agency relationship' (6) there is a sense that change is happening very slowly, and as P2 argues, there is 'a huge mountain to climb'.

The mothers also referred to being valued but in a slightly different way, namely by referring to communication and interactions in the playground. The extract below is from FG1M and is part of a discussion around engaging with practitioners and fellow parents when picking children up from day-care at the end of the day:

M1: When I pick up my child, you see little huddles of the mums and dads, and then you feel like you want to go out and speak to them and then they basically put their guards up. But, erm, at the end of the day, it's not like, 'I've done nothing wrong', just like, basically, they dont want to speak to you, because they dont know who you are or vice versa, but sometimes that makes you feel like you are not part of it, or being valued as worthy or something. So, I think, communication, sometimes it's down to a learning curve for, from date of birth onwards.

The playground is a conundrum of personalities and behaviours, which is portrayed vividly in Gill Hornby’s book 'The Hive' (2013), in which she illustrates examples of playground politics, social standing and cliques. Here, links can be made with family structures and related hierarchies, boundaries, subsystems and homeostasis, as well as social economic situation (5). Socioeconomic status (SES) is often measured as a combination of education, income, and occupation, and is commonly conceptualized as the social standing or class of an individual or group. Parenting is socially patterned, and when viewed through a social class lens, privilege, power, and control are emphasized (see Belsky et al., 2006).

\section{$\underline{\text { Relationships between parents and practitioners }}$}

In their discussions, participants frequently addressed the relationships between parents and practitioners. At the same time, there was a sense that this relationship is challenging at times. The extract below comes from a focus group with early years practitioners (FG2P), and is part of a discussion around parental behaviour and choices: 
P1: What is convenient, how early does it open, how late is it open, is it close to home. I think a lot of those are the priorities and will my child be happy, for some parents comes quite far down the list, and they think my child will adapt to it! Yet, it is the relationship we have with parents that is key here and the parents' willingness to engage for a child to settle in.

P2: I do think there are parents that don't necessarily choose on what will be best for their child. They chose what is going to fit in with what they have got to do.

Research consistently highlights the significance of parent-partnerships (see Hadley, 2012;

Whalley, 2007). This includes recognising parents as their child's primary educators and establishing ways to actively engage with parents (see also Whalley, 2007). As can be seen from the extract above, this can be tricky, because parents and practitioners may have different priorities. Thus, different factors need to be negotiated here, and family structures and related boundaries (5), as well psychological structures (4), such as the child's happiness, come into play.

This was also evident from the focus group interviews with the mothers (FG2M). The extract below is part of a discussion around engaging with early years practitioners and childminders:

M1: My little boy came home yesterday, I picked him up from the childminder, and he said to me, erm, 'mummy they all call me stupid', you see. Whatever I was doing, it was stupid, stupid, stupid, and he suffers a little bit, because he is a bit slower then the rest of them learning. He is, erm, he sort of said that to me, so that now I am wondering what was going on today, and she [childminder] didn't tell me.

M2: I think it is down to the practitioner or pre-school teachers to help them, and encourage as well, and let the parents know and stop the other children from making that person or child to be pinpointed.

The above shows that relationships between parents and practitioners are key in early years settings. Families and early years settings as contexts, can form protective factors and enhance the resilience of the child. This is reflected in government policy and key early years studies (DfE, 2015; Sylva et al., 2010) with a focus on improving developmental outcomes of children. Moreover, following Whalley (2007), it should be acknowledged that most parents 
appreciate practical help in identifying ways in which they can support their children. Thus, political agendas, including the status, knowledge and qualifications of early years workers (2), psychological factors, such as the child's wellbeing (4) and family structures and subsystems (5) are significant factors here.

\section{What happens at home:}

Participants viewed the home situation as an important factor in itself, both in relation to how parents engage with early years settings, and in fostering parent-practitioner partnerships. The next extract comes from a focus group with practitioners (FG3P) and is part of a discussion around settling in:

P1: Of course, how a child settles in and behaves in the setting very much depends on the home situation, and the relationship they have with their parents. Sometimes a child is dropped off in the setting and the parent can't wait to leave and get on with their things, no time to talk, no time to help them settle in.

P2: There was an article in TES a few years ago, where parents at a very small exclusive school in London were asked why they had chosen that school, and this was a school that took children from 5, I think it was a prep school, so 5-11. These are very well educated people, very smart people, career people and so many of them gave inane answers like, 'I liked the uniform' they were there because they liked the uniform. Another one said they chose the school because it had extra long school holidays and meant they could go away abroad on their holidays. I can remember reading it, and I don't believe what I am reading here but it was a true interview.

Here, direct links are made between the home-situation and family structure (5) and 'how a child settles in'. Bowlby's (2005) attachment research has been of significant influence in exploring social-emotional development in children, with subsequent studies and metaanalytic reviews (Fearon et al., 2010) showing links between the child's early relationships and future maladaptive and adaptive developmental outcomes. Some of this is reflected in the participants' suggestions that the home and family situation of the child play a key role in how the child behaves in the setting (4). In addition to this, by making links between the home situation and 'no time to talk, 'no time to help them settle in', there is a sense that a 
smooth transition from home to day-care is to an extent prevented by a lack of communication and engagement between the parents (mothers) and practitioners (6). Here, $\mathrm{P} 2$ refers to the fact that this can also be parents who are 'very well educated people, very smart people, career people', which is interesting in light of causal factors associated with self-esteem, academic achievement and self-efficacy(1).

The home situation and 'what happens at home' was also discussed by the mothers. The mothers focused on their role and responsibility as parents teaching their child how to behave, both at home and in the early years setting. The next example comes from FG3M and is part of a discussion around preparing young children for day-care:

M1: Obviously, if he is naughty in nursery, you feel bad as a parent, because at home you're disciplining them. You know, and then they do it in nursery, you know, you feel... they can be nasty to other children, and you're thinking, 'well, I'm doing what I can at home you know, I'm not just doing nothing.

In this extract, the link between 'what happens at home' and how the child gets on in the setting is extended to the accountability of the parents for their child's behaviour, the notion that parents are their child's first and foremost educators (Whalley, 2007). This can be also linked back to Bowlby's attachment theory, and the suggestion that children's early attachment relationships provide templates for their internal working model of the self and the world (Bowlby, 2005). Thus, parenting, family (5) and psychological structures (4) play a mediating role here.

\section{Child at the Centre:}

A 'child-centred approach' marked some of the earliest relationships between parents and practitioners, as well as playing a key role in the initial engagement between parents and practitioners. The first extract comes from a focus group interview with early years 
practitioners (FG2P), and is part of a discussion around introducing the child and parent to the setting:

P1: When I show parents round our setting, that is one of the things I say to them. All children are different and you may feel after having looked round that the setting isn't the right style for your child, you have to pick what suits

P3: Another interesting thing that came out was that the reason, parents, some mothers put their children into day-care, large nurseries, is the fact they don't want that child to get too attached to somebody because they want that attachment, but they aren't necessarily thinking that is good for the child.

In the extract above the 'uniqueness' of each child is emphasised and used as a starting point for the discussion with parents around whether the setting is suitable for their child. This child-centred approach is also one of starting points of the Early Years Foundation Stage (2017), the early years curriculum with a focus on every child as a unique child, who deserves the best possible start in life. Thus, it could be argued that in the initial interaction between parents and practitioners the causal dynamics stimulated by the early curriculum play (3) a significant role. Moreover, the psychological needs of the child (4) and family, specifically when it comes to boundaries and resilience (5) need to be taken into account here as well.

See below for an example from a focus group with mothers (FG1M), which also highlights the suitability of the setting and relation to the individual needs of the child. The extract is part of a discussion around day care and choice:

M2: Before our girls, before my girls started preschool, I used to take them round once a week and stay there with them, just so they got used to the environment and the teachers, and it was helpful

M3: Yes, me too. It was very helpful. 
The fact that this uniqueness of the child warrants an individual approach, is also evident in the extract below, from FG3M, in which a mother discusses how her child has benefitted from preschool:

M2: My three-year old, before he started preschool, he, you know, he would only stay with me and his dad and stuff. And when, even when we had family gatherings and stuff, it was more the confidence issue he had. And we were trying to get him, like get him to encourage him doing, you know, playing with other children and stuff. As soon as he started preschool, they have done so much work with him. As well as stuff at home, but just be with someone independent you know, to encourage him and him to talk more and interact more with other children and become confident.

The extract above shows how in an ideal situation, psychological factors, such as the child's needs, confidence and attachment (4), and family structures and resilience (5), as causal mechanisms and powers, play a mutual role in the relationships between parents and practitioners impacting both on the wellbeing of child, parents and practitioners. Parentpractitioner partnerships are marked by the 'un-known', as most of the time parents drop their child off and are not there when their child is in day-care. At the same time, a lot of learning and development happens in the home environment, a setting that practitioners are overall not part of (Cottle and Alexander, 2014). This is summed up in the last theme below.

\section{When I am not there:}

The first extract comes from a focus group interview with mothers (FG1M) and is part of a discussion around what happens (or may happen) in the setting when you are not there:

M1::I think that I probably have a filtered view of it, mostly from what they tell me and what they post on their website, as well as how the setting is rated overall. Basically, because I am not there, so I can sit here and say what is going on in the setting, but I don't know.

M2: True

M1: But it would be interesting to know exactly what is happening at pre-school when I am not there. 
This extract suggests that the 'filtered view' is influenced by causal dynamics associated with political agendas (2) and the early years curriculum (3), evident from the reference to how the setting is rated and what is posted on their websites. Yet, the suggestion here is that if relationships are to be truly reciprocal, there needs to be more mutual involvement, knowledge and understanding beyond what is available through social media and verbal communication. The extract below comes from FG2P and is part of a discussion around the child's home situation:

P1: I think, social background is important, because if parents aren't parenting them at home, telling them they do need to share, they do need to be gentle, or they might have a culture at home. For example, in this particular instance, a very very lovely family with children that are coming to pre-school, but daddy's' daddy's been taking his little boy boxing and he is only three, and he goes boxing, so it is natural to him to come in and want to box with the children because that is what he does with daddy. So for them, the family feel that is perfectly fine, and it wasn't until I chatted to mum, and I said, actually do you know that he is hitting other children and causing them damage. But they didn't realise that what they were doing was just building up and aggressive side of him. And it's that sort of stuff, you only really see the child in the setting and don't always know what is going on at home.

The extract above reinforces what was said earlier on about reciprocity and home structures namely that effective two-way communication is the key for building successful partnerships (Chu, 2017). It could be argued that although parent practitioner partnerships are an essential element in early years settings, the way this is understood and enacted by the various partners is very different (see also Cottle and Alexander, 2014). Whilst practitioners may be influenced by dominant policy and psychology discourses as well as their personal and professional histories and their perceptions of the purposes and priorities of their setting, parents may view that what happens outside of the setting is irrelevant in this context. This could lead to tensions and dilemmas around constructions of the role of practitioners and parents in child development, echoing the tensions within government policies, outlined above. Thus, parents and practitioners personal experiences and perceptions of their (professional) roles permeate both these areas (1-6). 


\section{Discussion \& Conclusion}

The current study focused on social processes and causal factors in relation to mothers' and practitioners' engagement with early years settings, by adopting a form of critical realist informed grounded theory. As Reichertz (2010) has noted, the abductive nature of grounded theory assumes an openness and flexibility of approach, with a fundamental premise to let the key issues emerge, rather than to force them into preconceived categories. Following Charmaz (2006), most grounded theory researchers aim to develop rich conceptual analysis of lived experience, and social worlds, instead of intending to create substantive or formal theory. Drawing upon retroductive argument, our CRGT framework sought to build an explanation of social processes and practices by identifying generative causal powers that underlie and shape this.

This research has provided insight into ways in which mothers and practitioners position themselves. Focused coding led to examples of themes that play a role in the lived experiences of both mothers and practitioners, namely being valued, relationships, what happens at home, child at the Centre and when I am not there. In line with CRGT, causal mechanisms were identified that were active in the situated contexts. Here, a stratified ontology was assumed, referring to CR's disctinction between the 'real', the 'actual' and the 'empirical', showing how phenomena exist at the level of events and experiences, but also at the deeper level that may not be observable. As such, through retroductive argumentation (see also Kempster and Parry, 2014) an explanation of social processes and practices in relation to mother/practitioner engagement with early years settings was generated, through identifying and explaining the underlying causal powers. For example, low status associated with the early years workforce in England, and issues to do with self-efficacy and academic 
self-concept, played a role in the themes 'being valued' and 'relationships between parents and practitioners'. Social issues to do with how practitioners are perceived by parents (i.e. in relation to their status and academic ability) have an impact on how parents are treating them, e.g. as a childcare worker, rather than a professional with knowledge and expertise in child development. This also needs to be viewed in light of the role and causal dynamics of political agendas (e.g. to raise the qualifications of early years practitioners) and the early years curriculum (DfE, 2017) and how this may (or may not) affect parent-practitioner relationships (e.g. in relation to expectations). Dynamics in social policy, where the focus appears to consistently be on how the early years workforce is lacking and in need of transformation, also play a role in parent-practitioner relationships (Allen, 2011; Osgood 2009). Psychological structures and discourses were also highlighted, especially in relation to the role of attachment and early relationships, with a specific link to the themes 'what happens at home' and 'child at the centre'. Family structure, needs of the family and SES were also highlighted, as well as structure-agency relationship, which includes morphogenesis and morphostasis.

Thus CRGT provides insight into phenomena and processes that emerge, as both contextualised and generative. It is the particular combination of internal and external causal factors that act as 'generative mechanisms' (Bhaskar, 1989) for phenomena. All phenomena can be explained in part by, but not reduced to, their underlying generative mechanisms (Oliver, 2012). This means that positioning in relationships between parents and early years practitioners may be generated in part by interrelated beliefs about status, self-esteem educational achievement and academic background, which may be generated in part by broader political and psychological discourses, which, in turn, emerge from the intersection of oppressive political and economic structures. Thus, multiple causal mechanisms, including 
the interpretations of each situation made by each individual, constantly interact with, negate and reinforce each other. It could be argued that in order to improve parent-partnerships, attention needs to paid to the psychological, social and political forces at play, as generative, causal and contextual powers, that have an impact on the status and relationships of the players within this triad (parents, practitioners and child).

The implicit warning for anyone adopting the GT method has always been not to get too far away from objectivity when explaining phenomena and resultant theory. Those people may say that the risk with critical realism is that we stray too far away from objectivity (Kempster and Parry, 2014). We would argue that by exploring causal mechanisms as both generative and contextual, we can explore how people manage themselves within a social context that is materially structured (e.g. the elemental, physical nature of the world), embodied (e.g. the body as a biological machine) and institutionally structured (e.g. government bodies, and the psy-complex) (Cromby and Nightingale, 1999). Despite various moves towards critical realist grounded theory, there have been a number of criticisms, namely in relation to the clash of epistemologies and lack of a systematic method. The purpose of this article was to engage with both criticisms by offering CRGT as a systematic tool for addressing both the event under study (in this case relationships between mothers and practitioners) and the meaning made of it, by viewing this in light of non-linear causal factors, social structures and generative mechanisms (embodied, material and institutional). Critical realist's primacy of ontology formed the starting point here, with grounded theory as the epistemological force providing critical realism's method and, in doing so, allowed us to contextualise research and embedding this more firmly into practice (see also Oliver, 2012). As such, this study has provided insight into the powers and mechanisms at play in mothers' and practitioners' engagement with and social relationships in the early years sector. More research is needed to explore parent-partnerships (including mothers and fathers) and underlying mechanisms, also 
with a view to strengthening relationships between parents and practitioners in early years settings.

\section{References}

Allen, G. (2011). Early Intervention: The Next Steps. An Independent Report to Her Majesty's Government. London: HM Government.

Apramian, T., Cristancho, S. and Watling, C. (2016). (Re)Grounding grounded theory: a close reading of theories in four schools. Qualitative Research. 17(4): 359-376. https://doi.org/10.1177/1468794116672914.

Bandura, A. (1997). Self-Efficacy: The exercise of control. New York: Freeman.

Barnes, J., Leach, P., Malmberg, L-E, Stein, A. and Sylva, K. and the FCCC Team (2009). Experiences of Childcare in England and socio-emotional development at 36 months. Early Child Development and Care, 180(9): 1215-1229.

Bate, A. (2017). Early Intervention (Briefing Paper No. 7647). London: House of Commons Library.

Baylin, J. (2017). Attachment-Focused treatment and the brain: A neuroscience Perspective. In K, Doyle Buckwalter and D, Reed (Eds.), Attachment Theory in Action: Building connections between Children and Parents, London: Rowman \& Littlefield, pp. 33-50.

Bhaskar, R. (1989). Reclaiming Reality. London: Verso.

Bhaskar, R. (2014). Foreword. In P. Edwards, J. O. Mahoney, \& S. Vincent (Eds.), Studying Organisations Using Critical Realism. A Practical Guide, Oxford: Oxford University Press, pp. V-XV.

Belsky, J., Bell, B.M., Bradkey, R.H., Stallard, N. and Steward-Brown, S.L. (2006).

Socioeconomic risk, parenting during the preschool years and child health age 6 years. The European Journal of Public Health, 508-513.

Bowlby, J. (2005). The Making and Breaking of Affectional Bonds. London/New York: Routledge.

Breckenridge, J. and Jones, D. (2009). Demystifying theoretical sampling in grounded theory research. Grounded Theory Review. An International Journal, 2.

Burr, W. R., Day, R. D., and Bahr, K. S. (1993). Family science. Pacific Groves, CA: Brooks/Cole.

Charmaz, K. (2006). Constructing Grounded Theory, London: Sage. 
Chu, S.Y. (2017). Perspectives from Both Sides of the Parent-Professional Partnership: A Preliminary Study on Taiwan's Early Childhood Special Education Services. International Journal of Disability, Development and Education, 1(1): 1-8. DOI: 10.1080/1034912X.2017.1403572.

Cottle, M. and Alexander, E. (2014). Parent partnership and 'quality' early years services: practitioners' perspectives. European Early Childhood Education Research Journal, 22(5): 637-659, DOI: 10.1080/1350293X.2013.788314.

Cromby, J. and Nightingale, D.J. (1999). What's wrong with social constructionism? In: D.J. Nightingale, and J. Cromby. (Eds.), Social Constructionist Psychology. A critical analysis of theory and practice, Buckingham: OU Press, pp. 1-20.

DfE. (2017). Statutory Framework for the Early Years Foundation Stage. Setting the Standards for Learning, Development and Care for children from birth to five. Retrieved from https://www.foundationyears.org.uk/files/2017/03/EYFS_STATUTORY_FRAMEWORK_2 017.pdf

Ebbeck, M. and Yim, H., Y., B. (2009). Rethinking Attachment: fostering positive relationships between infants, toddlers and their primary caregivers. Early Child Development and Care, 179(7): 899-909.

Elfer, P. and Dearnley, K. (2007). Nurseries and emotional well-being. Early Years. An International Journal of Research and Development. 27(3): 267-280.

Fearon, R.P., Bakermans-Kranenburg, M.J., van Ijzendoorn, M.H., Lapsley, A-M. and Roisman, G.I. (2010). The Significance of Insecure Attachment and Disorganization in the Development of Children's Externalizing Behaviour: A Meta-Analytic Study. Child Development, 81(2): 435-456.

Glaser, B.G. and Strauss, A.L. (1967). The Discovery of Grounded Theory: Strategies for Qualitative Research, Chicago, IL: Aldine.

Hadley, F. (2012) Early Childhood Staff and Families' Perceptions: diverse views about important experiences for children aged 3-5 years in early childhood settings. Contemporary Issues in Early Childhood, 13(1): 38-49.

Hornby, G. (2013). The Hive. London: Little Brown.

Howard, C. and Davies, P. (2013). Attracting mature students into higher education: The impact of approaches ot learning social identity. Journal of Further and Higher Education, 37(6): 769-785.

Jacoby, N. (2016). Socioeconomic Status Differences in Negative Emotions, Sociological Research Online, 22(2):6.

Keller, H. (2012). Autonomy and Relatedness Revisited: Cultural Manifestations of Universal Human Needs. Child Development Perspectives, 6(1): 12-18. 
Kempster, S.J. and Parry, K.W. (2011) Grounded Theory and Leadership Research: A Critical Realist Perspective, The Leadership Quarterly, 22: 106-120.

Kempster, S.J. and Parry, K.W. (2014) Critical Realism and Grounded Theory, In: Edwards, P., O.Mahoney, J and S. Vincent (Eds.) Studying Organisations Using Critical Realism. A Practical Guide, Oxford: Oxford University Press, 86-108.

Kennedy Reedy, C. and Hobbins McGrath, W. (2010) Can you hear me know? Staff-parent communication in child care centres, Early Child Development and Care, 180(3): 347-357.

Kessler, I. and Bach, S. (2014). Comparing Cases. In: Edwards, P.K., O’Mahoney, J. and Vincent, S. (Eds), Studying Organizations Using Critical Realism, Oxford: Oxford University Press, pp. 168-184.

Kitzinger, J. (1994) The Methodology of Focus Groups: The Importance of Interaction Between Participants, Sociology of Health and Illness, 16(1), 103 -121.

Kochanska, G and Kim, S. (2012). Early Attachment Organization with Both Parents and Future Behavior Problems: From Infancy to Middle Childhood. Child Development, 84(1), 283-296.

Lee, F. (2012). Critical realism, Grounded theory and theory construction in heterodox economics. MPRA Paper No. 40341, retrieved from http://mpra.ub.uni-muenchen.de/40341/

Mahadevan, J. (2011). EYFS has improved childcare in England, Ofsted finds. Children and Young People Now. Retrieved from http://www.cypnow.co.uk/news/1054139/EYFSimproved-childcare-England-Ofsted-finds.

Marsh, H. W., and Martin, A. J. (2011). Academic self-concept and academic achievement: Relations and causal ordering. British Journal of Educational Psychology. 81(1), 59-77.

Mason, Z.S., Briggs, R.D. and Silver, E.J. (2011). Maternal attachment feelings mediate between maternal reports of depression, infant social-emotional development and parenting stress. Journal of Reproductive and Infant Psychology. 29(4): 382-394.

Miller, V. (2015) Resonance as a Social Phenomenon, Sociological Research Online. 20(2): 9.

Nalls, A.M., Mullis, R.L., Cornille, T.A., Mullis, A.K. and Jeter, N. (2010). How can we reach reluctant parents in childcare programmes? Early Child Development and Care. 180(8): 1053-1064.

Nutbrown, C. (2012). Foundations for Quality. The independent review of early education and childcare qualifications. Final report. Runcan: Department of Education. Retrieved from: www.education.gov.uk/nutbrownreview.

Oliver, C. (2012). Critical Realist Grounded Theory: A New Approach for Social Work Research, The British Journal of Social Work, 42(2), 371- 387.

Osgood, J. (2009). Childcare workforce reform in England and the 'early years professional': a critical discourse analysis. Journal of Education Policy. 24(6): 733-751. 
Pitchforth, E., Porter, M., van Teijlingen E., and Forrest Keenan, K. (2005). Writing up and presenting qualitative research in family planning \& reproductive health care, Journal of Family Planning \& Reproductive Health Care 31(2), 132-35.

Reichertz, J. (2010). Abduction: the Logic of Discovery of Grounded Theory. Qualitative Social Research Sozialforschung, 11(1).

Sims-Schouten, W. (2016). Positioning in relationships between parents and early years practitioners, Early Child Development and Care, 186(9), 1392-1405.

Sims-Schouten, W. and Riley, S.E. (2014). Employing a form of critical realist discourse analysis for identity research: An example from women's talk of motherhood, childcare and employment. In: Edwards, P., O'Mahoney, J. and Vincent, S. (Eds.), Putting Critical Realism into Practice: A Guide to Research Methods in Organization Studies. Oxford: UOP.

Sims-Schouten, W. and Stittrich-Lyons, H. (2013). 'Talking the Talk' - Practical and Academic Self-Concepts of Early Years Practitioners in England, Journal of Vocational Education and Training, 66(1), 39-55.

Siraj-Blatchford, I. (2009). Quality teaching in the early years. In A. Anning, J. Cullen. \& M. Fleer. (Eds.), Early Childhood Education. Society and Culture (pp. 147-157). London: Sage

Spiteri, G. And Borg Xuereb, R. (2012). Going back to work after childbirth: women's lived experiences. Journal of Reproductive and Infant Psychology. 30(2), 201-216.

Sylva, K., Melhuish, E, Sammons, P., Siraj-Blatchford, I. and Taggart, B. (2010). Early Childhood Matters. Evidence from the Effective Pre-school and Primary Education project. London and New York: Routledge.

Whalley, M. (Ed.). (2007). Involving Parents in their Children's Learning. London: Paul Chapman. 